\title{
COVID-19-Associated Acute Brain Dysfunction Related to Sepsis
}

\author{
Dao Ming Tong ${ }^{\mathrm{a}, \mathrm{c}}$, Ye Ting Zhou ${ }^{\mathrm{b}}$, Yuan Wei Wang ${ }^{\mathrm{a}}$
}

\begin{abstract}
In global term, as of November 30, 2020, over 30 million people has been infected by a novel severe acute respiratory syndrome coronavirus 2 (SARS-CoV-2), and more than 10,000,000 of them died of acute organ failure. Our reviews have shown that coronavirus disease 2019 (COVID-19) patients with pneumonia and acute respiratory distress syndrome (ARDS) have life-threatening acute brain dysfunction (ABD), ranging from altered mental status/delirium to stupor/coma. Altered mental status/delirium was the most common manifestation of ABD caused by severe COVID-19. The prevalence of altered mental status and/or delirium was up to $66-79.5 \%$, and prevalence of coma was $10 \%$. The most common clinical type of COVID-19-associated ABD was COVID-19-associated acute stroke including ischemic and hemorrhagic stroke ( $\mathrm{n}>350$ cases), followed by COVID-19-associated encephalopathy ( $\mathrm{n}>200$ cases), and COVID-19-associated central nervous system (CNS) infection ( $\mathrm{n}>$ 70 cases). According to the Sepsis-3 criteria, we confess that severe COVID-19-associated ABD with ARDS and altered mental status is related to sepsis. Moreover, we also review the diagnosis and treatment of COVID-19-associated ABD with sepsis. In view of the fact that COVID-19 is at the peak of epidemic worldwide, we hope that this review will provide evidence of COVID-19 sepsis threating to the brain dysunction. Thus, recognizing the COVID-19-associated $\mathrm{ABD}$ related to sepsis is very important for early empirical combination therapy to survive severe COVID-19.
\end{abstract}

Keywords: COVID-19; Sepsis; Brain dysfunction; CNS infection; Encephalopathy; Mechanisms; Outcome

\section{Introduction}

The novel coronavirus, i.e., severe acute respiratory syndrome

Manuscript submitted February 4, 2021, accepted February 13, 2021

Published online February 25, 2021

a Department of Neurology, Affiliated Shuyang Hospital of Xuzhou Medical University, Jiangsu, China

bDepartment of Surgery, Affiliated Shuyang Hospital of Xuzhou Medical University, Jiangsu, China

${ }^{\mathrm{c} C}$ Corresponding Author: Dao-MingTong, Department of Neurology, Affiliated Shuyang Hospital of Xuzhou Medical University, No. 9 Yingbin Road, Shuyang, Jiangsu 223600, China. Email: tongdaoming@163.com

doi: https://doi.org/10.14740/jocmr4437 coronavirus 2 (SARS-CoV-2) causing coronavirus disease 19 (COVID-19), emerged as a public health threat in December 2019; and a global outbreak was declared by the World health Organization (WHO) in March 2020. In initial 35 days of COVID-19 outbreak in Wuhan, China, over 40,000 cases of COVID-19 were diagnosed by viral nucleic acid testing. The clinical features mostly included pneumonia with life-threatening respiratory failure, septic shock and/or multiple organ dysfunction [1]. As of May 29, 2020, 5.88 million cases with COVID-19 were confirmed, and 363,000 deaths were reported [2]. Unfortunately, according to the information from WHO, in recent months due to CVID-19 outbreak in several big countries, as of November 30, 2020, over 30 million people have been infected, and more than 1,000,000 of them died of acute organ failure; and its epidemic continues globally. The new Sepsis-3 criteria defined sepsis as a life-threatening organ dysfunction due to a dysregulated host response to infection [3]. Severe COVID-19 patients who met Sepsis-3 criteria were up to $59.0 \%$, and with mortality of $48.2 \%$ [4]. Although the most common presentation caused by COVID-19 is acute respiratory distress syndrome (ARDS), reports of acute brain dysfunction (ABD) are increasing. Severe COVID-19 infection can induce an inflammatory cytokine storm that results in COVID-19-associated neurological manifestation or neurological complications $[2,4,5]$. Moreover, SARS-CoV-2 presence in brain parenchyma has been found by autopsies [6], suggesting SARS-CoV-2 with an ability to enter into brain. The human brain is very vulnerable to inflammatory storm and hypoxemia. Tao Chen and colleagues provided their data indicating that COVID-19 patients with sepsis and with inflammatory storm and hypoxemia are at a high risk of death [7]. The central nervous system (CNS) manifestations caused by COVID-19 included dizziness (17\%), headache (13\%), impaired consciousness $(7.5 \%)$, seizures $(0.5 \%)$, and acute cerebrovascular disease (5.7\%) [8]. Moreover, altered mental status $(66.0 \%)$ was more likely to represent as the most common neurologic symptom [9]. Actually, according to the new definition of Sepsis-3, all above-mentioned manifestations can generally be called as COVID-19-associated ABD, including various different terms, such as altered mental status, delirium, cerebrovascular disease/stroke, encephalopathy, encephalitis and/or meningitis, and other conditions. However, the diagnosis of COVID-19-associated neurological manifestation is still very challenging. Moreover, some unspecified events of property also required to be classified. Thus, the aim of our review will address the current diagnostic trends of $\mathrm{ABD}$ related to COVID-19 sepsis. 


\section{Materials and Methods}

For this study, we reviewed all published reports on COVID19-associated ABD. We performed an extensive search of PubMed, Google Scholar, and preprint databases (medRxiv and bioRxiv). We identified single case reports, case series, cohort study, and multicenter study. We used search terms, including "COVID-19", "sepsis", "acute brain dysfunction", "CNS infection", "encephalopathy", "neurological manifestation", and "delirium or seizures". Full-text articles were acquired from journals' websites. We analyzed demographic, clinical, cerebrospinal fluid (CSF), and neuroimaging characteristics of patients who presented with COVID-19-associated ABD related to sepsis. The last search was done on November 30, 2020.

This study was approved by the Institutional Review Board at Affiliated Shuyang Hospital of Xuzhou Medical University (approval number: 1-2020-0013).

\section{Results}

\section{COVID-19-associated acute stroke}

Acute stroke was one of the most common ABD seen in COVID-19 populations. Although a 5.7\% [8] incidence of ischemic stroke has been recorded, its frequent events are still being reported. In a single center retrospective study of 221 COVID-19 patients from China, 13 (6\%) had acute stroke including 11 ischemic, one hemorrhagic and one venous sinus thrombosis [10]. In a single academic center from USA within 2 weeks after the positive result of polymerase chain reaction (PCR) testing, brain magnetic resonance imaging (MRI) findings showed that acute and subacute ischemic infarcts happened in $5.4 \%$ of the cases and acute hemorrhage in $4.5 \%$ [11].

Notably, in the study by Oxley and colleagues, five COVID-19 cases with large-vessel stroke (male in four cases, female in one cases; age range: 33 - 49 years) have been reported [12]. On admission, the mean National Institutes of Health Stroke Scale (NIHSS) of five cases was 17. Similarly, in May, five cases $(18.5 \%)$ of COVID-19-associated vasculopathy have also been reported [13]. MRI findings included diffuse involvement of deep white matter, the corpus callosum, and the basal ganglia.

Surprisingly, the prevalence of COVID-19-associated emergent large vessel occlusion (ELVO) stroke was up to 53\% [14]. These positive COVID-19 patients were younger, 75\% more likely to have radiographic evidence of apical lung abnormalities, and more likely to require mechanical ventilation due to respiratory failure.

A statistics from the Global COVID-19 Stroke Registry between January 27, 2020 and May 19, 2020 suggested that numbers of ischemic stroke was up to 174 patients (median age 71.2 years; $37.9 \%$ females) [15]. A recent report from multicenter case-control study in UK showed that 81 cases of ischemic stroke were more frequently to occur when compared to those ischemic controls in Asians ( $18.8 \%$ vs. $6.7 \%$, $\mathrm{P}<0.0002$ ), were more likely to involve multiple large ves- sel occlusions $(17.9 \%$ vs. $8.1 \%, \mathrm{P}<0.03)$, were more severe (median NIHSS score 8 vs. $5, \mathrm{P}<0.002$ ), were associated with higher $\mathrm{D}$-dimer levels $(\mathrm{P}<0.01)$, and were associated with more severe disability on discharge (median mRS score 4 vs. $3, \mathrm{P}<0.0001)$ and in-patient death $(19.8 \%$ vs. $6.9 \%, \mathrm{P}<$ $0.0001)[16]$.

In addition, a case series of five cases of COVID-19-associated intracerebral hemorrhage have been reported [17]. Moreover, a total of 35 out of 5,227 COVID-19 patients who had intracerebral hemorrhage (including acute subdural hematoma, subarachnoid hemorrhage, multi-compartmental hemorrhage, and multi-focal and focal intracerebral hemorrhage) have also been reported [18]. All 35 patients with severe COVID-19 presented with pneumonia requiring mechanical ventilation, and with a mortality of $35.3 \%$.

\section{COVID-19-associated acute encephalopathy}

COVID-19-associated encephalopathy has been found between March and May [19]. The authors reported two male patients (age > 70 years) with COVID-19 pneumonia with one requiring intubation for acute hypoxemic respiratory failure. Their characteristics included systemic inflammatory response, impaired consciousness (from delirium to lethargy). One did not show any acute lesion on brain image and another showed a small hyperintense signal lesion on diffusion-weighted images (DWI) in the left parietocoritcal region. Electroencephalographies (EEGs) of two cases were confirmed having diffused slowing. The CSF analysis of two patients did not show any evidence of CNS infection (i.e., normal cell count, negative PCR of COVID-19, and negative other microbes). The patients were treated in the intensive care unit (ICU) and with a poor outcome.

At the same period, 58 intensive care patients (median age 63 years) with COVID-19 with neurological features were reported by Helms et al [20]. Of them, seven patients had a CSF analysis without a pleocytosis and all with negative reverse transcriptase-polymerase chain reaction (RT-PCR) results for SARS-CoV-2. These authors concluded that only $12 \%$ of SARS-CoV-2 infection cases were associated with encephalopathy.

Notably, in May 2020, 20 patients with critical COVID19-associated encephalopathy have been reported [13]. All cases required intubation and were transferred to the respiratory ICU (RICU) due to respiratory failure (100\%) and impaired consciousness (96.3\%). Most of the cases of COVID-19-associated encephalopathy with COVID-19-associated vasculopathy (diffuse or multifocal subcortical lesions) were confirmed by computed tomography (CT)/MRI-DWI.

The first case of COVID-19-associated acute hemorrhagic necrotizing encephalopathy (ANE) with altered mental status was reported by Poyiadji et al [21]; DWI image showed hemorrhagic rim enhancing lesions in the bilateral thalami, medial temporal lobes, and subinsular regions. Moreover, CSF bacterial culture showed no growth, and tests for herpes simplex virus 1and 2, varicella-zoster virus, and West Nile virus were all negative. But, the test of COVID-19 in the CSF was not performed, and her CSF analysis was limited due to a trau- 
matic lumbar puncture. These authors considered that ANE is a rare encephalopathy caused by COVID-19 and other virus due to an intracranial cytokine storms.

In addition, a retrospective study from Wuhan described their data that 113 sepsis-deceased COVID-19 patients with respiratory failure/ARDS and hypoxemia; of which patients with hypoxic encephalopathy were at high risk of death $(20 \%$, 23/113) [7]. However, evidence of the so-called "hypoxic encephalopathy" was not reported on their CSF analysis and MRI images. Whereas, their data showed that those patients had severe systemic inflammatory response (fever, rapid respiratory and heart rates) and cytokine storm (increased tumor necrosis factor in blood), at least suggesting that encephalopathy may be caused by the cytokine storm and hypoxemia.

\section{COVID-19-associated CNS infection}

COVID-19-associated CNS infection included acute encephalitis, acute meningoencephalitis, and acute meningitis, which is not rare during the COVID-19 outbreak. A 24-year-old COVID-19-positive man with pneumonia and severe hypoxia required intubation was reported as the first case of acute encephalitis [22]. Moreover, he was in coma and his CSF analysis showed a white cell count of 12 cells and with positive PCR for COVID-19. At the same time, DWI and fluid-attenuated inversion recovery (FLAIR) images showed hyperintense signal changes in the right temporal and hippocampus.

Subsequently, as of November 30, more than $10 \mathrm{COV}$ ID-19 cases with encephalitis/meningoencephalitis/meningitis have been reported [23-32]. The median age was 42 years (range from 6 months to 72 years). Of them, nine patients had a CSF analysis, with an increased pleocytosis in seven cases, elevated protein in eight cases, and elevated levels of interleukin (IL)-6 in two cases. Three patients had positive PCR in CSF. All cases had negative CSF culture. Only two cases did not have CSF analysis. But, one with chest CT showed COVID-19 pneumonia, and a 24-h EEG showed an excess of left temporal sharp waves in EEG, and the other with brain lesion biopsy was confirmed with the diagnosis of COVID-19-associated acute encephalitis.

More recently, a total of eight encephalitis cases were reported by Helms et al [33]. The CSF analysis confirmed that abnormal CSF included elevated nucleated cell count in three cases, elevated CSF protein levels in eight cases, elevated IL-6 levels in six cases, and positive SARS-CoV-2 RT-PCR in CSF in one case.

From multicenter study, it was found that about $13-32 \%$ of all COVID-19 patients suffered from encephalitis [34, 35]. In fact, its incidence may be severely underestimated because about 70\% COVID-19 patients did not performed CSF examination.

COVID-19-associated acute disseminated encephalomyelitis and immune-mediated encephalitis

Notably, the COVID-19-associated acute disseminated en- cephalomyelitis has been found [36, 37]. Moreover, Paterson et al [38] reported a total of nine cases of acute disseminated encephalomyelitis in 29 SARS-CoV-2 PCR-positive cases, suggesting its incidence is not rare. In addition, some cases of COVID-19 associated post-infectious immune-mediated encephalitis and rare acute hemorrhagic leukoencephalitis were also reported [39-41].

\section{Unspecified COVID-19-ABD}

In a series of 58 COVID-19 patients with neurological features [20], $49(84.5 \%)$ patients experienced no confirmed neurological diagnosis due to without CSF analysis. These unspecified brain symptoms included altered mental status and/or corticospinal tract signs. Similarly, among 118 (79.5\%) COVID-19 ICU patients with pneumonia, delirium, and/or abnormal neurological examination [33], brain MRIs were performed in 32 cases; and new ischemic events in 28 cases were found. CSF analysis was performed in 25 out of the 32 patients. Finally, these authors considered that most of them were not sure whether delirium or encephalopathy, except for 28 ischemic stroke and eight cases of encephalitis. Thus, almost $70 \%$ of patients with delirium and/or corticospinal tract signs were unspecified diagnosis.

Seizures are common in COVID-19 patients [8, 27, 42]. A 59-year-old man with a SARS-CoV-2 infection confirmed by RT-PCR assay performed on tracheal secretions and by CT scan of the chest was reported [43]. The illness rapidly progressed to hypoxemic respiratory failure warranting the initiation of invasive mechanical ventilation. Subsequently, the patient started to exhibit short episodes of impaired consciousness together with confusion. EEG showed two widespread long rhythmic delta discharges with superimposed spikes in predominantly frontal localization, followed by a moderate interictal frontal activity, leading to the diagnosis of non-convulsive status epileptics. Brain MRI was normal, routine CSF analysis was unremarkable, and CSF SARS-CoV-2 RT-PCR was negative. Clobazam (30 mg/day) and levetiracetam (1.5 $\mathrm{g}$ /day) were introduced. On April 14, the patient had only one brief episode of impaired consciousness and EEG monitoring was normal. He is now clinically stable and discharged from ICU.

All above reports have fully supported this fact that severe COVID-19 patients are related to COVID-19-associated ABD. Their clinical evidences are summarized in Table $1[3,13,22-$ $33,36-39,44,45]$.

\section{Sepsis is related to severe COVID-19-associated ABD}

As of November 30, 2020, according to the results of our study, the most common clinical type of COVID-19-associated ABD was COVID-19-associated acute stroke $(n>350)$, followed by COVID-19-associated encephalopathy ( $\mathrm{n}>200)$, and COVID19 -associated CNS infection $(n>70)$.

Although infection is a common risk factor that may induce acute stroke [46, 47], the high rates of the current 


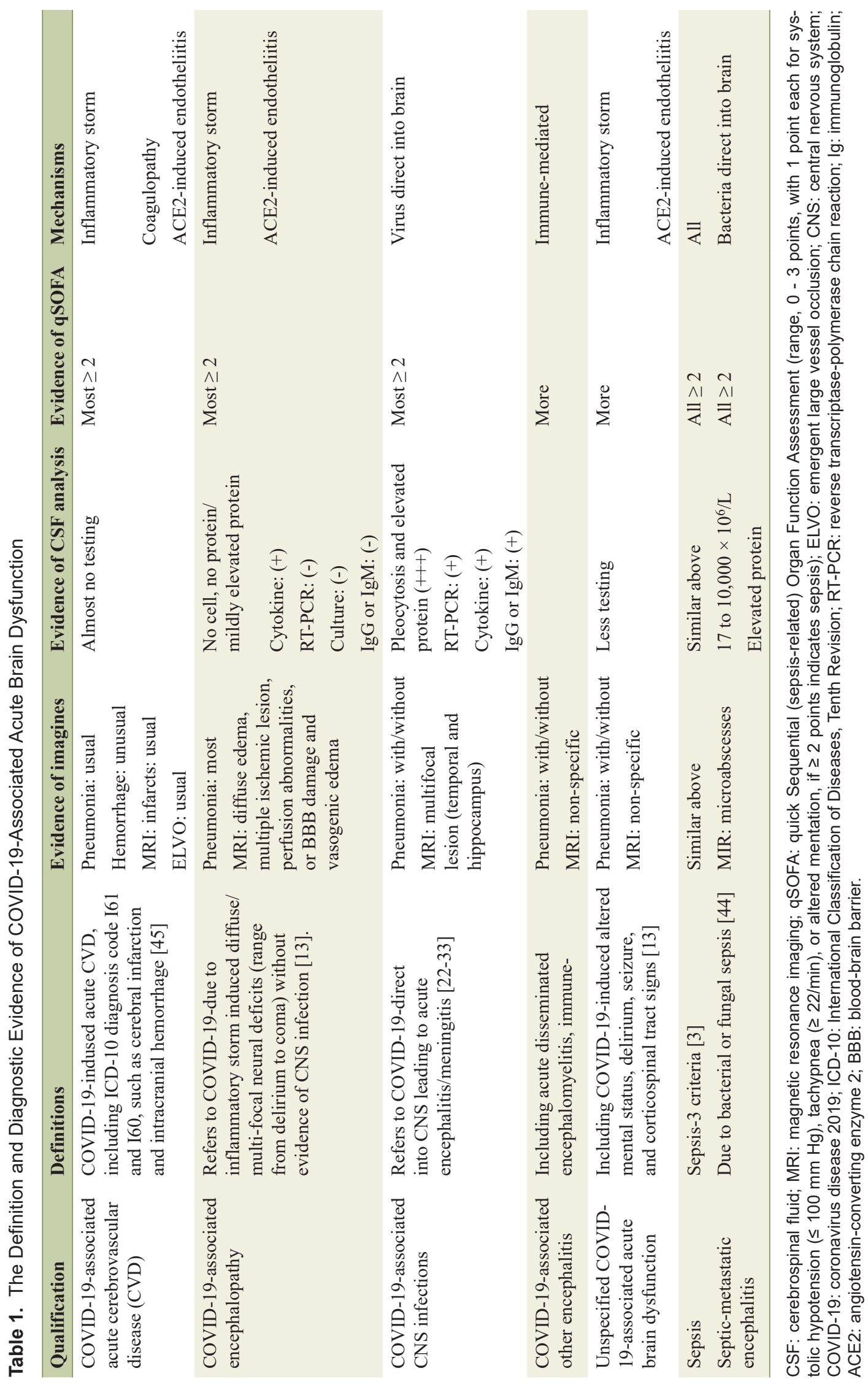


COVID-19-associated acute stroke is also related to the other potential risk factors, including hypertension, diabetes, heart disease, chronic pulmonary disease, and obesity [4, 5, 48, 49]. Yet, its mechanisms are also related to the severe inflammation storm/cytokines storm, coagulopathy, angiotensin-converting enzyme 2 (ACE2)-induced endothelial dysfunction/ endotheliitis [50-54]. Moreover, most COVID-19-associated acute stroke due to acute respiratory failure/ARDS and altered mental status met the clinical criteria of Sepsis-3. However, whether presenting virus directly enters into the brain is unclear because the CSF examinations were not performed for all cases. Therefore, further study on CSF has to be analyzed for those COVID-19-associated stroke patients.

COVID-19-associated CNS infection is also common because of the increasing evidence that viruses can enter into brain by multi-route directly [22, 54-57]. The data of current review also confirmed that COVID-19-associated CNS infection is a frequent event, and this number is increasing. Furthermore, the differential diagnosis of COVID-19-associated encephalitis and COVID-19-associated encephalopathy is still hard to manipulate for clinicians. Although previous study indicated that encephalopathy caused by sepsis is related to inflammatory cytokine storm which results in blood-brain barrier (BBB) leakage and brain edema [52], the recent study has confirmed that an endothelialitis in the brain is also responsible for the COVID-19-associated encephalopathy [58]. However, the severe COVID-19-associated encephalopathy/ encephalitis, like severe COVID-19-associated acute stroke, is overall related to sepsis.

Indeed, sepsis-associated ABD is highlighted in the current COVID-19 pandemic trends [56-61]. According to the clinical criteria of Sepsis-3, i.e., quick Sequential (sepsis-related) Organ Function Assessment (qSOFA: range, 0 - 3 points, with 1 point each for tachypnea ( $\geq 22 / \mathrm{min}$ ), altered mentation, or systolic hypotension $(\leq 100 \mathrm{~mm} \mathrm{Hg})$, if $\geq 2$ points indicates sepsis) [3], most severe COVID-19-associated ARDS and altered mentation have fully met the diagnose of sepsis $[4,7,13$, 62-64]. Moreover, the ARDS play pivotal roles in the development of multiple organ dysfunction syndrome (MODS) in septic event $[65,66]$. The previous studies showed that sepsis with MODS were more likely to exhibit an ABD [52, 67-69]. However, recent studies indicated that almost 50-57.9\% COVID-19 patients developed secondary bacterial infections [13, 70, 71]. Only 3.5-16.7\% COVID-19 cases had a confirmed community-acquired bacterial infection $[72,73]$. In fact, based on previous reports, a mixed sepsis was not rare [74, 75]. Also, the animal models of the mixed sepsis have been established successfully [76]. Furthermore, during the COVID-19 outbreak, the cases with mixed sepsis were also more frequently reported [77-80].

\section{Early identification of sepsis: neutrophils, lymphocytes, and inflammatory storm}

Important question remained to identify the mixed sepsis rapidly, because a delay in initiating antibiotic treatment was related to early high mortality in the ICU study [81], and with
$7 \%$ rise in risk of death for every hour of delay [82]. Therefore, faster and more accurate pathogen identification is critical $[83,84]$. Unfortunately, the early diagnosis of sepsis only relies upon a clinician suspecting infection rather than cultures. Even in patients whose cultures will be positive, there is a time differences from hours to days between the time points when the sample is sent and the one when the positive result is obtained.

To our best knowledge, the neutrophils are the first line of defense against bacterial pathogens. The increased number of neutrophils in the peripheral blood is a critical sign for bacterial sepsis [85-87]; whereas, there is often a significant decreased lymphocytes in the peripheral blood for viral sepsisdeceased patient $[4,7,88,89]$. Rapid diagnosis of bacterial infection is mainly based on elevated neutrophils numbers of circulating, which is more likely to be related to patients with suspected bacterial sepsis $[90,91]$. Clinically, severe inflammatory storms (high fever, rapid respiratory and heart rates, and elevated cytokines or other inflammatory markers) usually represent the sign of a suspected bacterial sepsis or mixed sepsis [92-95]. Even there have been given a combination treatment for COVID-19 mixed infections, specific therapy of septic ABD involves the accurate diagnostic test, suggesting that bacteriological tests has to be still performed for patients with bacterial sepsis, so as to target accurate antibiotic therapy.

More importantly, accurate diagnosis also needs to be made based on evidence of CSF analysis. In the data of current review, almost $70 \%$ of the cases did not have CSF examination, which is more likely to be the reason of missed diagnosis of CNS infection. Clinically, severe inflammatory storms lasting days to weeks could also represent the sign of microbes have been entered into brain [96-98]. Therefore, it is important to bear in mind that the CSF examination should be carried out for patients with refractory inflammatory storm. Moreover, the CSF analysis is also an important evidence for the identification of COVID-19-associated encephalitis and septic-metastatic encephalitis caused by bacterial or fungal sepsis $[44,99]$.

The CSF analysis results for COVID-19-associated encephalitis showed mainly an increased lymphocytic pleocytosis and elevated CSF protein as well as positive RT-PCR or intrathecal antibody production (immunoglobulin M (IgM), IgG) [33, $34,65]$. Moreover, the CSF change of other viral encephalitis (such as influenza viruses and herpes zoster virus) also presented with similar features with that of COVID-19-associated CNS infection. Whereas, for septic-metastatic encephalitis, its CSF analysis indicated an elevated leukocyte counts (median $473 \times 10^{6} / \mathrm{L}$, range from 17 to $10,000 \times 10^{6} / \mathrm{L}$ ), and elevated CSF protein level (median $7.39 \mathrm{~g} / \mathrm{L}$, range from 4.78 to 42.49 $\mathrm{g} / \mathrm{L}$ ) [99]. Notably, for encephalopathy caused by any infection, its CSF analysis only indicates a mildly elevated protein level, and normal white cell count as well as negative PCR, and without other evidence of direct CNS infection [19, 20, 38].

\section{Empirical combination therapeutics}

The data of current review have fully suggested that SARS$\mathrm{CoV}-2$-associated multiple organ dysfunction is called as 
COVID-19 sepsis (viral sepsis). Based on the Sepsis-3 criteria, viral sepsis may also be defined as one or more life-threatening organ failure caused by viral infection, but at least bacterial sepsis needs to be excluded [100]. Like COVID-19 sepsis with $\mathrm{ABD}$, influenza viruses, herpes zoster virus, and other viruses may also result in viral sepsis with ABD (altered mental status) [101-103]. Despite the qSOFA is a useful tool for early prediction of prehospital sepsis in patients with $\mathrm{ABD}$, it is still unpredictable from infection to mixed sepsis and whether microorganisms enter into the brain. Therefore, in these complex situations, early empirical combination therapy must be considered $[64,102]$, including more than one broad-spectrum antibiotics (a beta-lactam + fuoroquinolone or aminoglycoside), antiviral agents (remdesivir, lopinavir/ritonavir), and immunosuppressor. Dexamethasone is a broad-spectrum immunosuppressor and it would limit the production of and damaging effect of the cytokines. Moreover, dexamethasone would block macrophages from clearing secondary, nosocomial infections. Hence, dexamethasone may be useful for the short-term in COVID-19 sepsis with severe inflammatory storm and intubation respiratory [104-106].

Despite the presentation of septic-metastatic encephalitis on MRI is mainly microabscesses [107], its CSF analysis indicated a severe bacterial meningoencephalitis [99], suggesting that using high-doses vancomycin for the therapy of septicmetastatic encephalitis/meningitis must be considered [108110], and combination dexamethasone therapy is also need [111]. In short, empirical treatment is limited, and faster and more accurate pathogen identification is essential.

For COVID-19 sepsis with severe ARDS, especially those with lung and brain edema cases, veno-venous extracorporeal membrane oxygenation may be used as a very important support to save lives $[112,113]$.

\section{Conclusions}

The current trends of severe COVID-19 outbreak have shown that COVID-19-associated ABD related to sepsis is threatening to human' life. Globally, the most common COVID-19-associated ABD is COVID-19-associated acute stroke, followed by COVID-19-associated encephalopathy, and COVID-19-associated CNS infection. Thus, recognizing the COVID-19-associated $\mathrm{ABD}$ as a life-threatening organ dysfunction related to sepsis is very important for early empirical combination therapy to save severe COVID-19 patient. However, it is necessary to explore further its pathogenesis, laboratory diagnosis, and treatment.

\section{Acknowledgments}

None to declare.

\section{Financial Disclosure}

None to declare.

\section{Conflict of Interest}

The authors declare that they have no conflict of interest.

\section{Author Contributions}

TDM and ZYT conceptualized and designed the study, drafted the initial article, and reviewed and revised the article. All authors approved the final article as submitted and agree to be accountable for all aspects of the work.

\section{Data Availability}

The datasets used and/or analyzed during the current study are available from the corresponding author on reasonable request.

\section{References}

1. $\mathrm{Wu} \mathrm{Z,} \mathrm{McGoogan} \mathrm{JM.} \mathrm{Characteristics} \mathrm{of} \mathrm{and} \mathrm{important}$ lessons from the coronavirus disease 2019 (COVID-19) outbreak in China: summary of a report of 72314 cases from the Chinese Center for Disease Control and Prevention. JAMA. 2020;323(13):1239-1242.

2. Koralnik IJ, Tyler KL. COVID-19: a global threat to the nervous system. Ann Neurol. 2020;88(1):1-11.

3. Singer M, Deutschman CS, Seymour CW, Shankar-Hari M, Annane D, Bauer M, Bellomo R, et al. The third international consensus definitions for sepsis and septic shock (Sepsis-3). JAMA. 2016;315(8):801-810.

4. Zhou F, Yu T, Du R, Fan G, Liu Y, Liu Z, Xiang J, et al. Clinical course and risk factors for mortality of adult inpatients with COVID-19 in Wuhan, China: a retrospective cohort study. Lancet. 2020;395(10229):1054-1062.

5. Bhaskar S, Sinha A, Banach M, Mittoo S, Weissert R, Kass JS, Rajagopal S, et al. Cytokine storm in COVID19-immunopathological mechanisms, clinical considerations, and therapeutic approaches: the REPROGRAM consortium position paper. Front Immunol. 2020;11:1648.

6. Remmelink M, De Mendonca R, D'Haene N, De Clercq $\mathrm{S}$, Verocq C, Lebrun L, Lavis $\mathrm{P}$, et al. Unspecific postmortem findings despite multiorgan viral spread in COVID-19 patients. Crit Care. 2020;24(1):495.

7. Chen T, Wu D, Chen H, Yan W, Yang D, Chen G, Ma $\mathrm{K}$, et al. Clinical characteristics of 113 deceased patients with coronavirus disease 2019: retrospective study. BMJ. 2020;368:m1091.

8. Mao L, Jin H, Wang M, Hu Y, Chen S, He Q, Chang J, et al. Neurologic manifestations of hospitalized patients with coronavirus disease 2019 in Wuhan, China. JAMA Neurol. 2020;77(6):683-690.

9. Tyson B, Erdodi L, Ray S, Agarwal P. Altered mental status in 71 deaths due to COVID-19. Int J Neurosci. 2020:1-4.

10. Li YW, Zhou Y, Jiang C, et al. Acute cerebrovescular disease following in COVID-19: a single center, retrospec- 
tive, observational study. Lancet. 2020.

11. Radmanesh A, Raz E, Zan E, Derman A, Kaminetzky M. Brain Imaging Use and Findings in COVID-19: A Single Academic Center Experience in the Epicenter of Disease in the United States. AJNR Am J Neuroradiol. 2020;41(7):1179-1183.

12. Oxley TJ, Mocco J, Majidi S, Kellner CP, Shoirah H, Singh IP, De Leacy RA, et al. Large-vessel stroke as a presenting feature of COVID-19 in the young. N Engl J Med. 2020;382(20):e60.

13. Scullen T, Keen J, Mathkour M, Dumont AS, Kahn L. Coronavirus 2019 (COVID-19)-associated encephalopathies and cerebrovascular disease: the new orleans experience. World Neurosurg. 2020;141:e437-e446.

14. Majidi S, Fifi JT, Ladner TR, Lara-Reyna J, Yaeger KA, Yim B, Dangayach N, et al. Emergent large vessel occlusion stroke during New York City's COVID-19 outbreak: clinical characteristics and paraclinical findings. Stroke. 2020;51(9):2656-2663.

15. Ntaios G, Michel P, Georgiopoulos G, Guo Y, Li W, Xiong $\mathrm{J}$, Calleja P, et al. Characteristics and outcomes in patients with COVID-19 and acute ischemic stroke: the global COVID-19 stroke registry. Stroke. 2020;51(9):e254e258.

16. Perry RJ, Smith CJ, Roffe C, Simister R, Narayanamoorthi S, Marigold R, Willmot M, et al. Characteristics and outcomes of COVID-19 associated stroke: a UK multicentre case-control study. J Neurol Neurosurg Psychiatry. 2021;92(3):242-248.

17. Benger M, Williams O, Siddiqui J, Sztriha L. Intracerebral haemorrhage and COVID-19: Clinical characteristics from a case series. Brain Behav Immun. 2020;88:940944.

18. Altschul DJ, Unda SR, de La Garza Ramos R, Zampolin R, Benton J, Holland R, Fortunel A, et al. Hemorrhagic presentations of COVID-19: risk factors for mortality. Clin Neurol Neurosurg. 2020;198:106112.

19. Espinosa PS, Rizvi Z, Sharma P, Hindi F, Filatov A. neurological complications of coronavirus disease (COVID-19): encephalopathy, MRI brain and cerebrospinal fluid findings: case 2. Cureus. 2020;12(5):e7930.

20. Helms J, Kremer S, Merdji H, Clere-Jehl R, Schenck $\mathrm{M}$, Kummerlen C, Collange $\mathrm{O}$, et al. Neurologic features in severe SARS-CoV-2 infection. N Engl J Med. 2020;382(23):2268-2270.

21. Poyiadji N, Shahin G, Noujaim D, Stone M, Patel S, Griffith B. COVID-19-associated acute hemorrhagic necrotizing encephalopathy: imaging features. Radiology. 2020;296(2):E119-E120.

22. Moriguchi T, Harii N, Goto J, Harada D, Sugawara H, Takamino J, Ueno M, et al. A first case of meningitis/encephalitis associated with SARS-Coronavirus-2. Int J Infect Dis. 2020;94:55-58.

23. Duong L, Xu P, Liu A. Meningoencephalitis without respiratory failure in a young female patient with COVID-19 infection in Downtown Los Angeles, early April 2020. Brain Behav Immun. 2020;87:33.

24. Dugue R, Cay-Martinez KC, Thakur KT, Garcia JA, Chauhan LV, Williams SH, Briese T, et al. Neurologic manifestations in an infant with COVID-19. Neurology. 2020;94(24):1100-1102.

25. Huang YH, Jiang D, Huang JT. SARS-CoV-2 detected in cerebrospinal fluid by PCR in a case of COVID-19 encephalitis. Brain Behav Immun. 2020;87:149.

26. Bernard-Valnet R, Pizzarotti B, Anichini A, Demars Y, Russo E, Schmidhauser M, Cerutti-Sola J, et al. Two patients with acute meningoencephalitis concomitant with SARS-CoV-2 infection. Eur J Neurol. 2020;27(9):e43e44.

27. Sohal S, Mansur M. COVID-19 Presenting with Seizures. IDCases. 2020;20:e00782.

28. Wong PF, Craik S, Newman P, Makan A, Srinivasan K, Crawford E, Dev D, et al. Lessons of the month 1: A case of rhombencephalitis as a rare complication of acute COVID-19 infection. Clin Med (Lond). 2020.

29. Bodro M, Compta Y, Llanso L, Esteller D, Doncel-Moriano A, Mesa A, Rodriguez A, et al. Increased CSF levels of IL-1beta, IL-6, and ACE in SARS-CoV-2-associated encephalitis. Neurol Neuroimmunol Neuroinflamm. 2020;7(5).

30. Gallacher SD, Seaton A. Meningococcal meningitis and COVID-19 co-infection. BMJ Case Rep. 2020;13(8).

31. Efe IE, Aydin OU, Alabulut A, Celik O, Aydin K. COVID-19-Associated Encephalitis Mimicking Glial Tumor. World Neurosurg. 2020;140:46-48.

32. Ye M, Ren Y, Lv T. Encephalitis as a clinical manifestation of COVID-19. Brain Behav Immun. 2020;88:945946.

33. Helms J, Kremer S, Merdji H, Schenck M, Severac F, Clere-Jehl R, Studer A, et al. Delirium and encephalopathy in severe COVID-19: a cohort analysis of ICU patients. Crit Care. 2020;24(1):491.

34. Kremer S, Lersy F, Anheim M, Merdji H, Schenck M, Oesterle H, Bolognini F, et al. Neurologic and neuroimaging findings in patients with COVID-19: A retrospective multicenter study. Neurology. 2020;95(13):e1868-e1882.

35. Varatharaj A, Thomas N, Ellul MA, Davies NWS, Pollak TA, Tenorio EL, Sultan M, et al. Neurological and neuropsychiatric complications of COVID-19 in 153 patients: a UK-wide surveillance study. Lancet Psychiatry. 2020;7(10):875-882.

36. Parsons T, Banks S, Bae C, Gelber J, Alahmadi H, Tichauer M. COVID-19-associated acute disseminated encephalomyelitis (ADEM). J Neurol. 2020;267(10):2799-2802.

37. Reichard RR, Kashani KB, Boire NA, Constantopoulos E, Guo Y, Lucchinetti CF. Neuropathology of COVID-19: a spectrum of vascular and acute disseminated encephalomyelitis (ADEM)-like pathology. Acta Neuropathol. 2020;140(1):1-6.

38. Paterson RW, Brown RL, Benjamin L, Nortley R, Wiethoff $\mathrm{S}$, Bharucha T, Jayaseelan DL, et al. The emerging spectrum of COVID-19 neurology: clinical, radiological and laboratory findings. Brain. 2020;143(10):3104-3120.

39. Guilmot A, Maldonado Slootjes S, Sellimi A, Bronchain M, Hanseeuw B, Belkhir L, Yombi JC, et al. Immune-mediated neurological syndromes in SARS-CoV-2-infected patients. J Neurol. 2020.

40. Wang M, Li T, Qiao F, Wang L, Li C, Gong Y. Coronavi- 
rus disease 2019 associated with aggressive neurological and mental abnormalities confirmed based on cerebrospinal fluid antibodies: A case report. Medicine (Baltimore). 2020;99(36):e21428.

41. Yong MH, Chan YFZ, Liu J, Sanamandra SK, Kheok SW, Lim KC, Sewa DW. A Rare Case of Acute Hemorrhagic Leukoencephalitis in a COVID-19 Patient. J Neurol Sci. 2020;416:117035.

42. Najjar S, Najjar A, Chong DJ, Pramanik BK, Kirsch C, Kuzniecky RI, Pacia SV, et al. Central nervous system complications associated with SARS-CoV-2 infection: integrative concepts of pathophysiology and case reports. J Neuroinflammation. 2020;17(1):231.

43. Balloy G, Leclair-Visonneau L, Pereon Y, Magot A, Peyre A, Mahe PJ, Derkinderen P. Non-lesional status epilepticus in a patient with coronavirus disease 2019. Clin Neurophysiol. 2020;131(8):2059-2061.

44. Tauber SC, Djukic M, Gossner J, Eiffert H, Bruck W, Nau R. Sepsis-associated encephalopathy and septic encephalitis: an update. Expert Rev Anti Infect Ther. 2021;19(2):215-231.

45. World Health Organization international classification of disease, ICD-10. 1994.

46. Paganini-Hill A, Lozano E, Fischberg G, Perez Barreto M, Rajamani K, Ameriso SF, Heseltine PN, et al. Infection and risk of ischemic stroke: differences among stroke subtypes. Stroke. 2003;34(2):452-457.

47. Shao IY, Elkind MSV, Boehme AK. Risk factors for stroke in patients with sepsis and bloodstream infections. Stroke. 2019;50(5):1046-1051.

48. Docherty AB, Harrison EM, Green CA, Hardwick HE, Pius R, Norman L, Holden KA, et al. Features of 20133 UK patients in hospital with covid-19 using the ISARIC WHO Clinical Characterisation Protocol: prospective observational cohort study. BMJ. 2020;369:m1985.

49. Ko JY, Danielson ML, Town M, Derado G, Greenlund KJ, Daily Kirley P, Alden NB, et al. Risk Factors for COVID-19-associated hospitalization: COVID-19-associated hospitalization surveillance network and behavioral risk factor surveillance system. Clin Infect Dis. 2020.

50. Zhou Z, Kang H, Li S, Zhao X. Understanding the neurotropic characteristics of SARS-CoV-2: from neurological manifestations of COVID-19 to potential neurotropic mechanisms. J Neurol. 2020;267(8):2179-2184.

51. Hess DC, Eldahshan W, Rutkowski E. COVID-19-Related Stroke. Transl Stroke Res. 2020;11(3):322-325.

52. Shulyatnikova T, Verkhratsky A. Astroglia in sepsis associated encephalopathy. Neurochem Res. 2020;45(1):8399.

53. Kennedy JR. Phosphatidylserine's role in Ebola's inflammatory cytokine storm and hemorrhagic consumptive coagulopathy and the therapeutic potential of annexin V. Med Hypotheses. 2020;135:109462.

54. Kim KS. Mechanisms of microbial traversal of the bloodbrain barrier. Nat Rev Microbiol. 2008;6(8):625-634.

55. Disson $\mathrm{O}$, Lecuit M. Targeting of the central nervous system by Listeria monocytogenes. Virulence. 2012;3(2):213-221.

56. Kanellopoulos A, Ahmed MZ, Kishore B, Lovell R, Hor- gan C, Paneesha S, Lloyd R, et al. COVID-19 in bone marrow transplant recipients: reflecting on a single centre experience. Br J Haematol. 2020;190(2):e67-e70.

57. Varga Z, Flammer AJ, Steiger P, Haberecker M, Andermatt R, Zinkernagel AS, Mehra MR, et al. Endothelial cell infection and endotheliitis in COVID-19. Lancet. 2020;395(10234):1417-1418.

58. Pugin D, Vargas MI, Thieffry C, Schibler M, Grosgurin O, Pugin J, Lalive PH. COVID-19-related encephalopathy responsive to high-dose glucocorticoids. Neurology. 2020;95(12):543-546.

59. Li H, Liu L, Zhang D, Xu J, Dai H, Tang N, Su X, et al. SARS-CoV-2 and viral sepsis: observations and hypotheses. Lancet. 2020;395(10235):1517-1520.

60. Mehta P, McAuley DF, Brown M, Sanchez E, Tattersall RS, Manson JJ, Hlh Across Speciality Collaboration UK. COVID-19: consider cytokine storm syndromes and immunosuppression. Lancet. 2020;395(10229):1033-1034.

61. Gupta A, Madhavan MV, Sehgal K, Nair N, Mahajan S, Sehrawat TS, Bikdeli B, et al. Extrapulmonary manifestations of COVID-19. Nat Med. 2020;26(7):1017-1032.

62. Beltran-Garcia J, Osca-Verdegal R, Pallardo FV, Ferreres J, Rodriguez M, Mulet S, Ferrando-Sanchez C, et al. Sepsis and coronavirus disease 2019: common features and anti-inflammatory therapeutic approaches. Crit Care Med. 2020;48(12):1841-1844.

63. Thomas-Ruddel D, Winning J, Dickmann P, Ouart D, Kortgen A, Janssens U, Bauer M. Coronavirus disease 2019 (COVID-19): update for anesthesiologists and intensivists March 2020. Anaesthesist. 2020.

64. Rhodes A, Evans LE, Alhazzani W, Levy MM, Antonelli M, Ferrer R, Kumar A, et al. Surviving sepsis campaign: international guidelines for management of sepsis and septic shock: 2016. Crit Care Med. 2017;45(3):486-552.

65. McLean JS, Byrick RJ. ARDS and sepsis-definitions and new therapy. Can J Anaesth. 1993;40(7):585-590.

66. Crippa IA, Subira C, Vincent JL, Fernandez RF, Hernandez SC, Cavicchi FZ, Creteur J, et al. Impaired cerebral autoregulation is associated with brain dysfunction in patients with sepsis. Crit Care. 2018;22(1):327.

67. Gofton TE, Young GB. Sepsis-associated encephalopathy. Nat Rev Neurol. 2012;8(10):557-566.

68. Eidelman LA, Putterman D, Putterman C, Sprung CL. The spectrum of septic encephalopathy. Definitions, etiologies, and mortalities. JAMA. 1996;275(6):470-473.

69. Esen F, Orhun G, Ozcan PE, Brenes Bastos AR, Tuzun E. Diagnosing acute brain dysfunction due to sepsis. Neurol Sci. 2020;41(1):25-33.

70. Zhang H, Zhang Y, Wu J, Li Y, Zhou X, Li X, Chen H, et al. Risks and features of secondary infections in severe and critical ill COVID-19 patients. Emerg Microbes Infect. 2020;9(1):1958-1964.

71. Kimmig LM, Wu D, Gold M, Pettit NN, Pitrak D, Mueller J, Husain AN, et al. IL6 inhibition in critically ill COVID-19 patients is associated with increased secondary infections. medRxiv. 2020.

72. Vaughn VM, Gandhi T, Petty LA, Patel PK, Prescott HC, Malani AN, Ratz D, et al. Empiric antibacterial therapy and community-onset bacterial co-infection in patients 
hospitalized with COVID-19: a multi-hospital cohort study. Clin Infect Dis. 2020.

73. Hughes S, Troise O, Donaldson H, Mughal N, Moore LSP. Bacterial and fungal coinfection among hospitalized patients with COVID-19: a retrospective cohort study in a UK secondary-care setting. Clin Microbiol Infect. 2020;26(10):1395-1399.

74. Mihaljevic L, Bedenic B, Mihaljevic S, Majerovic M, Petrovic P, Vasilj I. Microbiological surveillance of the surgical intensive care unit in Zagreb-a pivot for guideline-based therapy of severe sepsis. Coll Antropol. 2007;31(4):1093-1097.

75. Kalil AC, Thomas PG. Influenza virus-related critical illness: pathophysiology and epidemiology. Crit Care. 2019;23(1):258.

76. Luhm J, Kirchner H, Rink L. One-way synergistic effect of low superantigen concentrations on lipopolysaccharide-induced cytokine production. J Interferon Cytokine Res. 1997;17(4):229-238.

77. Antinori S, Galimberti L, Milazzo L, Ridolfo AL. Bacterial and fungal infections among patients with SARSCoV-2 pneumonia. Infez Med. 2020;28(suppl 1):29-36.

78. Song G, Liang G, Liu W. Fungal co-infections associated with global COVID-19 pandemic: a clinical and diagnostic perspective from China. Mycopathologia. 2020;185(4):599-606.

79. Sepulveda J, Westblade LF, Whittier S, Satlin MJ, Greendyke WG, Aaron JG, Zucker J, et al. Bacteremia and Blood Culture Utilization during COVID-19 Surge in New York City. J Clin Microbiol. 2020;58(8).

80. Araujo OR, Almeida CG, Lima-Setta F, Prata-Barbosa A, Colleti Junior J, Brazilian Research Network in Pediatric Intensive Care. The impact of the novel coronavirus on Brazilian PICUs. Pediatr Crit Care Med. 2020;21(12):1059-1063.

81. Seymour CW, Gesten F, Prescott HC, Friedrich ME, Iwashyna TJ, Phillips GS, Lemeshow S, et al. Time to Treatment and Mortality during Mandated Emergency Care for Sepsis. N Engl J Med. 2017;376(23):2235-2244.

82. Kumar A, Roberts D, Wood KE, Light B, Parrillo JE, Sharma S, Suppes R, et al. Duration of hypotension before initiation of effective antimicrobial therapy is the critical determinant of survival in human septic shock. Crit Care Med. 2006;34(6):1589-1596.

83. Timbrook TT, Morton JB, McConeghy KW, Caffrey AR, Mylonakis E, LaPlante KL. The effect of molecular rapid diagnostic testing on clinical outcomes in bloodstream infections: a systematic review and meta-analysis. Clin Infect Dis. 2017;64(1):15-23.

84. Stevenson M, Pandor A, Martyn-St James M, Rafia R, Uttley L, Stevens J, Sanderson J, et al. Sepsis: the LightCycler SeptiFast Test MGRADE(R), SepsiTest and IRIDICA BAC BSI assay for rapidly identifying bloodstream bacteria and fungi - a systematic review and economic evaluation. Health Technol Assess. 2016;20(46):1-246.

85. Snall J, Linner A, Uhlmann J, Siemens N, Ibold H, Janos $\mathrm{M}$, Linder A, et al. Differential neutrophil responses to bacterial stimuli: Streptococcal strains are potent inducers of heparin-binding protein and resistin-release. Sci Rep.
2016;6:21288

86. Milot E, Fotouhi-Ardakani N, Filep JG. Myeloid nuclear differentiation antigen, neutrophil apoptosis and sepsis. Front Immunol. 2012;3:397.

87. Ljungstrom L, Pernestig AK, Jacobsson G, Andersson R, Usener B, Tilevik D. Diagnostic accuracy of procalcitonin, neutrophil-lymphocyte count ratio, C-reactive protein, and lactate in patients with suspected bacterial sepsis. PLoS One. 2017;12(7):e0181704.

88. Terpos E, Ntanasis-Stathopoulos I, Elalamy I, Kastritis E, Sergentanis TN, Politou M, Psaltopoulou T, et al. Hematological findings and complications of COVID-19. Am J Hematol. 2020;95(7):834-847.

89. Toniati P, Piva S, Cattalini M, Garrafa E, Regola F, Castelli F, Franceschini F, et al. Tocilizumab for the treatment of severe COVID-19 pneumonia with hyperinflammatory syndrome and acute respiratory failure: A single center study of 100 patients in Brescia, Italy. Autoimmun Rev. 2020;19(7):102568.

90. Liu L, Sun B. Neutrophil pyroptosis: new perspectives on sepsis. Cell Mol Life Sci. 2019;76(11):2031-2042.

91. Hong KS, Lee KH, Chung JH, Shin KC, Choi EY, Jin HJ, Jang JG, et al. Clinical features and outcomes of 98 patients hospitalized with SARS-CoV-2 Infection in Daegu, South Korea: a brief descriptive study. Yonsei Med J. 2020;61(5):431-437.

92. Carson WFt, Kunkel SL. Regulation of cellular immune responses in sepsis by histone modifications. Adv Protein Chem Struct Biol. 2017;106:191-225.

93. Meneses G, Cardenas G, Espinosa A, Rassy D, PerezOsorio IN, Barcena B, Fleury A, et al. Sepsis: developing new alternatives to reduce neuroinflammation and attenuate brain injury. Ann N Y Acad Sci. 2019;1437(1):43-56.

94. Divani AA, Andalib S, Di Napoli M, Lattanzi S, Hussain MS, Biller J, McCullough LD, et al. Coronavirus Disease 2019 and Stroke: Clinical Manifestations and Pathophysiological Insights. J Stroke Cerebrovasc Dis. 2020;29(8):104941.

95. Kogelmann K, Jarczak D, Scheller M, Druner M. Hemoadsorption by CytoSorb in septic patients: a case series. Crit Care. 2017;21(1):74.

96. Bastos MS, Coelho-Dos-Reis JG, Zauli DA, Naveca FG, Monte RL, Pimentel JP, Macario VM, et al. Divergent cerebrospinal fluid cytokine network induced by nonviral and different viral infections on the central nervous system. BMC Infect Dis. 2015;15:345.

97. Savarin C, Bergmann CC. Fine Tuning the Cytokine Storm by IFN and IL-10 Following Neurotropic Coronavirus Encephalomyelitis. Front Immunol. 2018;9:3022.

98. Pennisi M, Lanza G, Falzone L, Fisicaro F, Ferri R, Bella R. SARS-CoV-2 and the nervous system: from clinical features to molecular mechanisms. Int J Mol Sci. 2020;21(15).

99. Bitsch A, Nau R, Hilgers RA, Verheggen R, Werner G, Prange HW. Focal neurologic deficits in infective endocarditis and other septic diseases. Acta Neurol Scand. 1996;94(4):279-286.

100. Lin GL, McGinley JP, Drysdale SB, Pollard AJ. Epidemiology and Immune Pathogenesis of Viral Sepsis. Front 
Immunol. 2018;9:2147.

101. Xi X, Xu Y, Jiang L, Li A, Duan J, Du B, Chinese Critical Care Clinical Trial G. Hospitalized adult patients with 2009 influenza A(H1N1) in Beijing, China: risk factors for hospital mortality. BMC Infect Dis. 2010;10:256.

102. Paksu MS, Aslan K, Kendirli T, Akyildiz BN, Yener N, Yildizdas RD, Davutoglu M, et al. Neuroinfluenza: evaluation of seasonal influenza associated severe neurological complications in children (a multicenter study). Childs Nerv Syst. 2018;34(2):335-347.

103. VanderVeen N, Nguyen N, Hoang K, Parviz J, Khan T, Zhen A, Jagger BW. Encephalitis with coinfection by Jamestown canyon virus (JCV) and varicella zoster virus (VZV). IDCases. 2020;22:e00966.

104. Alhazzani W, Moller MH, Arabi YM, Loeb M, Gong MN, Fan E, Oczkowski S, et al. Surviving Sepsis Campaign: guidelines on the management of critically ill adults with Coronavirus Disease 2019 (COVID-19). Intensive Care Med. 2020;46(5):854-887.

105. Theoharides TC, Conti P. Dexamethasone for COVID-19? Not so fast. J Biol Regul Homeost Agents. 2020;34(3):1241-1243.

106. Solinas C, Perra L, Aiello M, Migliori E, Petrosillo N. A critical evaluation of glucocorticoids in the management of severe COVID-19. Cytokine Growth Factor Rev. 2020;54:8-23.
107. Gupta RK, Nath K, Prasad A, Prasad KN, Husain M, Rathore RK, Husain N, et al. In vivo demonstration of neuroinflammatory molecule expression in brain abscess with diffusion tensor imaging. AJNR Am J Neuroradiol. 2008;29(2):326-332.

108. Young N, Thomas M. Meningitis in adults: diagnosis and management. Intern Med J. 2018;48(11):1294-1307.

109. Ng K, Mabasa VH, Chow I, Ensom MH. Systematic review of efficacy, pharmacokinetics, and administration of intraventricular vancomycin in adults. Neurocrit Care. 2014;20(1):158-171.

110. Nau R, Djukic M, Spreer A, Ribes S, Eiffert H. Bacterial meningitis: an update of new treatment options. Expert Rev Anti Infect Ther. 2015;13(11):1401-1423.

111. de Gans J, van de Beek D, European Dexamethasone in Adulthood Bacterial Meningitis Study I. Dexamethasone in adults with bacterial meningitis. N Engl J Med. 2002;347(20):1549-1556.

112. Thakkar A, Parekh K, El Hachem K, Mohanraj EM. A case of MDMA-associated cerebral and pulmonary edema requiring ECMO. Case Rep Crit Care. 2017;2017:6417012.

113. Schmidt M, Hajage D, Lebreton G, Monsel A, Voiriot G, Levy D, Baron E, et al. Extracorporeal membrane oxygenation for severe acute respiratory distress syndrome associated with COVID-19: a retrospective cohort study. Lancet Respir Med. 2020;8(11):1121-1131. 